\title{
Centralized Power Generation of Solar Parks using Wireless Controlling
}

\author{
Anand M. Sharan\#*, Mohammad Zamanlou^, Md. Habibur Rahman^^ and Mohammad A. A. Al-Mehdi^ \\ \#Mechanical Engineering Department, ^Electrical Engineering Department, Faculty of Engineering, Memorial University of, Newfoundland, St. \\ John's, Newfoundland, Canada A1B 3X5
}

Received 12 March 2019, Accepted 15 May 2019, Available online 17 May 2019, Vol.9, No.3 (May/June 2019)

\begin{abstract}
In this paper, solar energy based power plant is operated from a centralized location. From this location, signal is sent to various tracking machines having solar panels mounted on them to track the Sun from 6 A.M. to 6 P.M. This tracking is based on spin rate of the earth, which is not based on local atmospheric conditions; in our case, the tracking is based on global conditions (earth motions around the Sun). This process is different from normally used photo-sensor based tracking. The tracking machine is designed such that the torque of the motor is minimum due to mass balancing effect. This process is different from other tracking processes where each machine operates independent of each other. In this case likelihood of the occurrence of fault becomes many fold. The maintenance of such plants is very laborious and inefficient.
\end{abstract}

Keywords: Photovoltaic panels electrical power generation, Solar tracking, Centralized control, Wireless applied micro controlling

\section{Introduction}

Solar energy in recent times, is being used very extensively (Statistics Key World ...., 2016, https://www.iea.org/publications/freepublications/p ublication/KeyWorld2017.pdf), (Senol,M. et.al., 2016), (Global status report,2017, http://www.ren21. net/gsr_2017_full_report_en). The prices of solar panels have come down very drastically. While the solar panels are becoming cheaper, the attention on the world's carbon dioxide levels has become very critical. The result is that the world's opinion on combustion of fossil fuels has gone to a new level. This is due to the fear of global warming and climate change (Department of Energy- Global Energy Storage Database, 2016, www.energystorageexchange.org), (Zhang,K et. al., 2019 ) , (Hou, J.C., et.al., 2018 ).

The Fig. 1 shows a solar park where large number of solar panels are being used for generating electricity. The way these are used, in northern hemisphere, that these panels are fixed at an angle equal to the latitude of the place of use and pointing directly to the south. On the other hand, in the southern hemisphere, it will be inclined at an angle equal to the latitude of the place but pointing to the north.

*Corresponding author's ORCID ID: 0000000313368333 DOI: https://doi.org/10.14741/ijcet/v.9.3.9

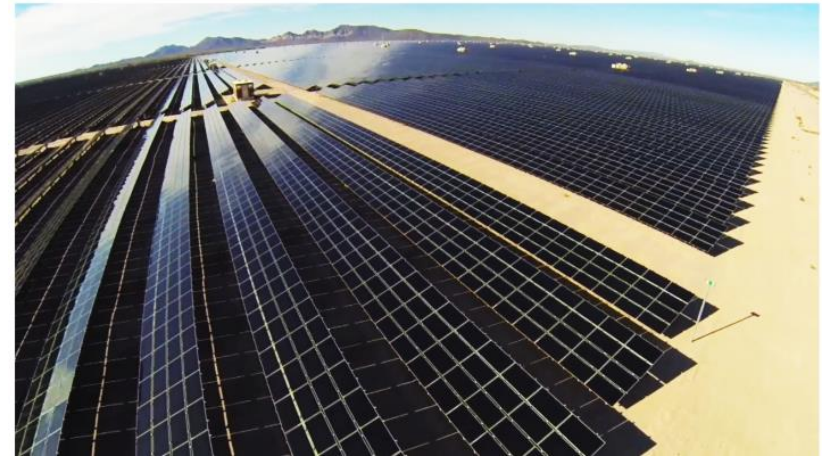

Fig.1 Photovoltaic TAIC panels in a solar park

The fixed panels do not generate electricity based on their rating (Sharan, A.M., 2008). The rating is based on the Sun's rays incident on the panel from the normal direction. This is the condition of maximum power generation. However, in reference 7 , it was concluded that the stationary panels on an average generate only $66.67 \%$ of their rating during a year. The only way to generate the rated power is by using a tracking system using gear boxes (Figs 2A and 2B) where the Sun's rays are normal to the panels. In such tracking systems, provision is made to change the orientation of the panel in three dimensions shown in Fig. 2C. 


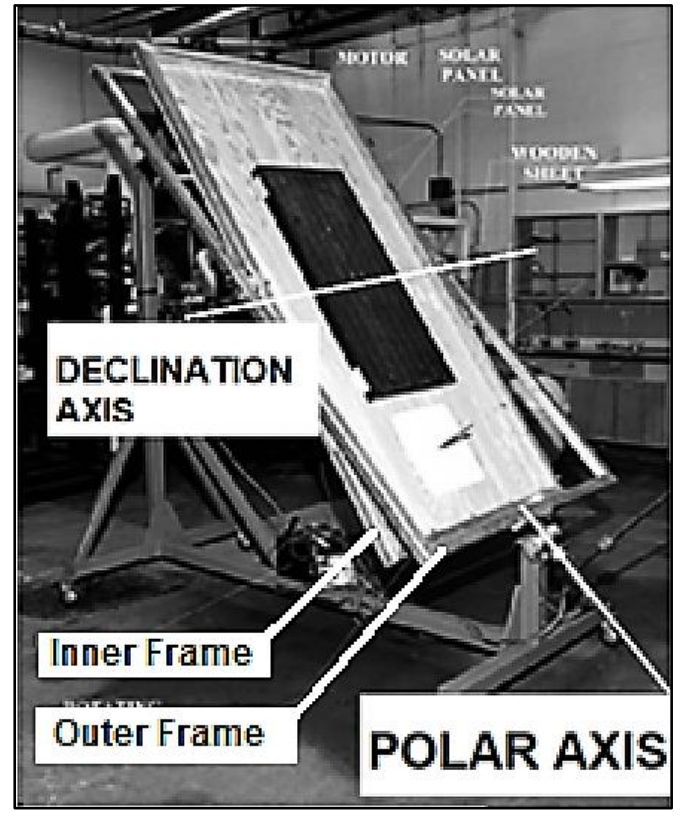

Fig.2A Tracking Machine

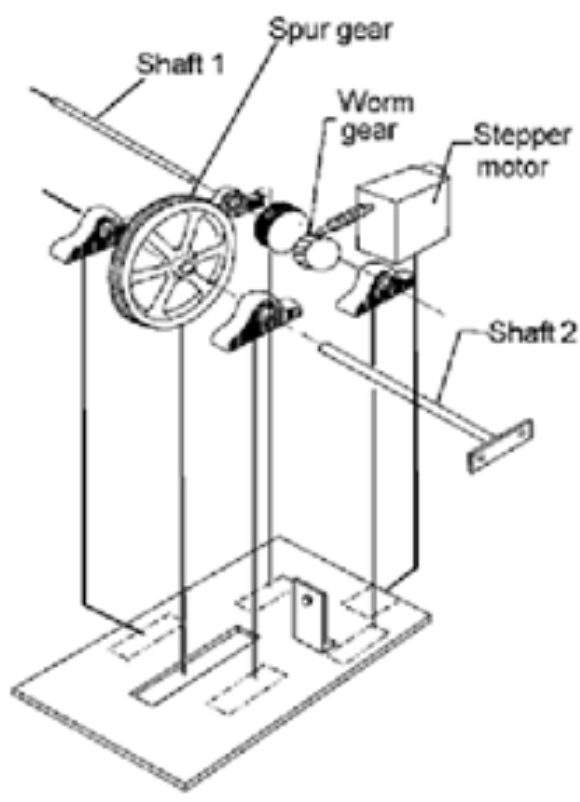

Fig.2B Gear reduction

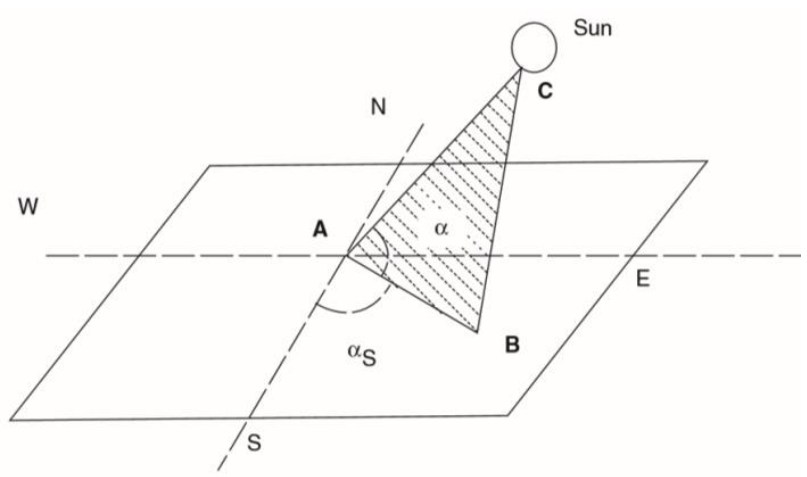

Fig.2C The direction of sun's rays are represented by a horizontal angle $\alpha_{\mathrm{s}}$ and vertical angle $\alpha$
At any location, the Sun rises from the east and sets in the west but the two angles of this direction, $\alpha$ and $\alpha_{s}$, as shown in Fig. 2C, keep on changing from sunrise to sunset simultaneously. Therefore, for maximum power generation, we have to continuously change the orientation of the solar panels so that the Sun's rays are normal to the panels. This type of simultaneous variation of angles is called two-axis tracking or dualaxis tracking (Aziz, S. and Hassan, M., 2019 ), (Zhan, T.S. et.al. 2013 ), (Chakrabory ). S., 2015), The principle used for the best alignment is the maximum intensity of light i.e. a photo sensor is used. Another way is to measure the maximum power generation.

Such systems are not very reliable under foggy, dusty, or moist conditions. Similarly, when there is a scattered cloud, then also the photo sensor becomes unreliable as it points towards the maximum intensity of light which may be coming from the area of the sky where the cloud is broken up. In such situations, if the sky becomes clear, then realigning the system towards the Sun requires large angular displacements which cannot be achieved very quickly due to the limited horse power of the tracking motors. If the number of solar panels is large, then the torque requirements of the motors increase.

Another way of aligning the solar panels is using single-axis tracking (Cooke,D., 2011), (Sharan, A.M.,and Prateek, M. , 2006) In this work, there are two axes, the first one is the polar axis, and the second one which is the right angle to the first one is used for changing declination (refer to Figs. 2A and 2B). The rate of change of declination from day to day is extremely small (refer to Fig. 2D).

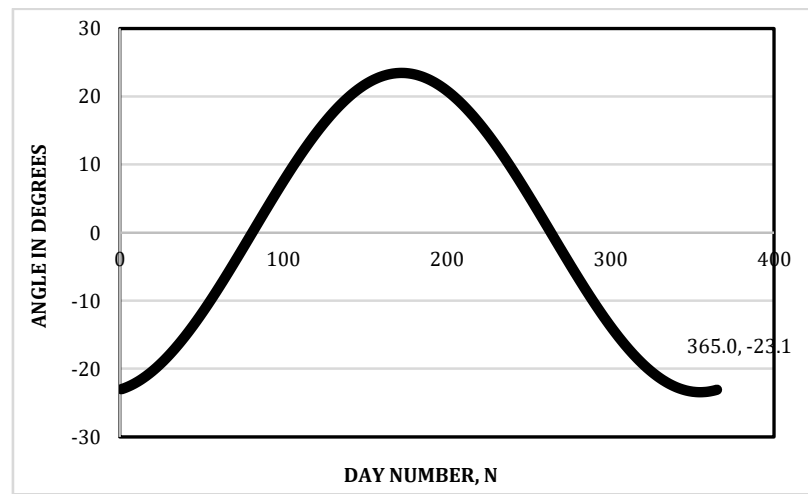

Fig.2D Declination variation versus day number $\mathrm{N}$

In Fig. 2A, there are two frames: inner frame rotates inside the outer frame about the declination axis, and the outer frame is inclined from the horizontal at an angle equal to the latitude of the place. It is the outer frame which is rotated for tracking purposes using a gearbox shown in Fig.2B. Considering this reduction, which a ratio of 1:20 in a worm and worm gear set and 15:100 in spur gear set, a stepper motor having step angle of 1.8 degrees was selected for daily tracking. Again, the declination was changed using a gear reduction of 1 to 20 in worm and worm gear in the 
machine and 1 to 64 in the declination stepper motor, which in overall comes to 1 to 1280 . Considering this reduction, a stepper motor having step angle of 5.625 degrees was selected for declination.

If we see the Fig. $2 \mathrm{~A}$, the change in torque due to the tracking rotation is minimal because of the mass balancing about the rotational axis (polar axis). This balancing was possible due to the symmetry of the frames about the polar axis as well as a counterweight arrangement on the rotational shaft beyond the lower bearing. In this way, after mounting the solar panels on the frames the residual imbalance was removed by the small counterweight which was screwed on a bolt fixed at right angles to the rotating shaft. This optimized any horse power requirements on the tracking motor. This motor rotates in steps of the pulses, and this rotation is very accurate and it does not require any feedback unlike other DC motors. Secondly, the accuracy is very high due to small angular displacement of the stepper motors which decreases the angular displacement of the solar panel by ratio of 1:133.333 due to the gear box as shown in the Fig. 2B which equals to 0.0135 degrees in the panel.

The added advantage here is that there is no simultaneous variation of two angles as in the case of dual-axis tracking. At a given time, one rotates the outer frame at the spin rate of the earth but the opposite direction of the rotation of the earth.

Due to the mass balancing about the tracking axis, large number of solar panels can be mounted on the inner frame which is not possible in any other methods of tracking systems.

In Fig. 1 there are large number of solar panels in the solar park and it would require several of these tracking machines to mount all of these. The result is that the area over which the tracking machines are located at is very spread out. So managing these tracking machines requires a very compact method of power generation (see Fig. 3).
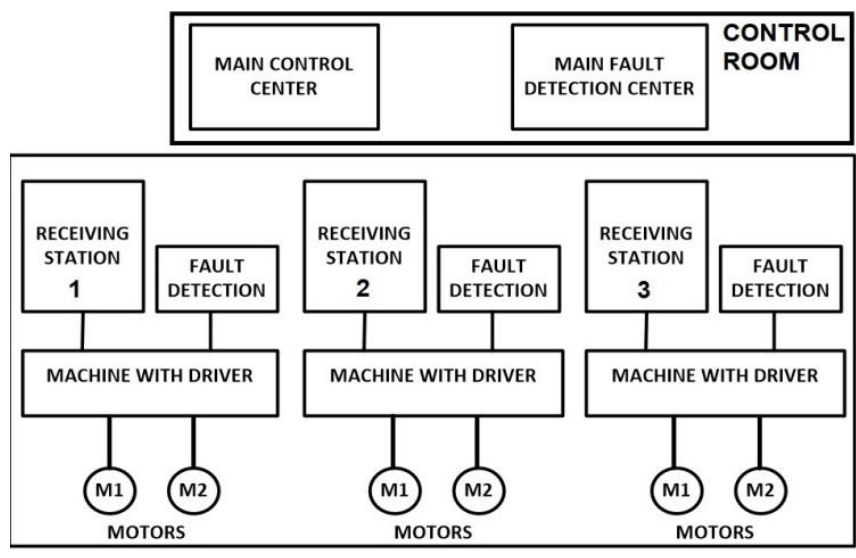

Fig.3 Compact arrangement where there is a Main Control Center (MCC)

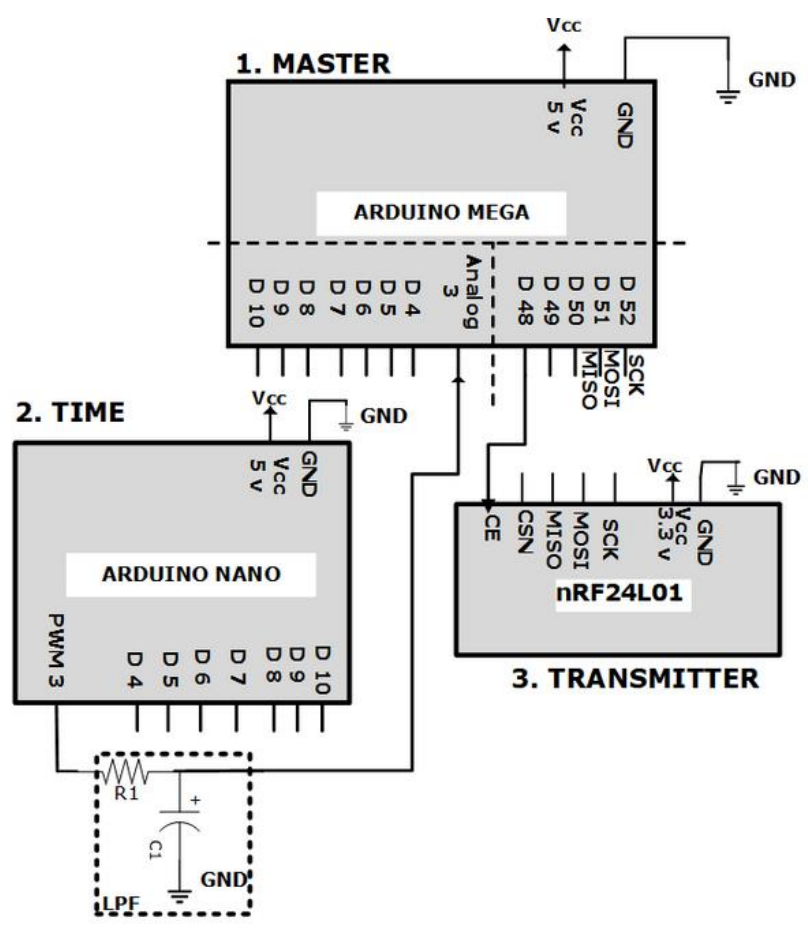

Fig.4 Master Control unit

Also, shown in this figure is an attached unit called Main Fault Detection Center (MFDC). This arrangement is similar to what one observes in thermal power plants or hydro power plants where the details of the operation can be seen in one control room. The purpose of MFDC is to constantly monitor any fault in the power generation. This is achieved by receiving a signal wirelessly from any of the machines where a fault has occurred. This matter is for the discussion later on in this paper.

The entire operation of tracking and declination adjustments is done wirelessly from MCC. Here, appropriate signals are continuously sent wirelessly to each of the machines where motors turn the solar panels for tracking purposes. In other words, a single source operates the entire power plant. This is not possible in any other methods of power generation where the optimal alignment of the panels is done locally in each of the machines such as those relying on photo-sensors. This distinction of this plant is because the optimal operation of the plant is based not on the local conditions such as the brightest spot in the sky but on the spin rate of the earth itself which is independent of the local conditions.

\section{Experimentation}

\subsection{Motion Analysis}

Fig. 5 shows the layout of the plant where the MCC and the MFDC are shown in the top layer. 


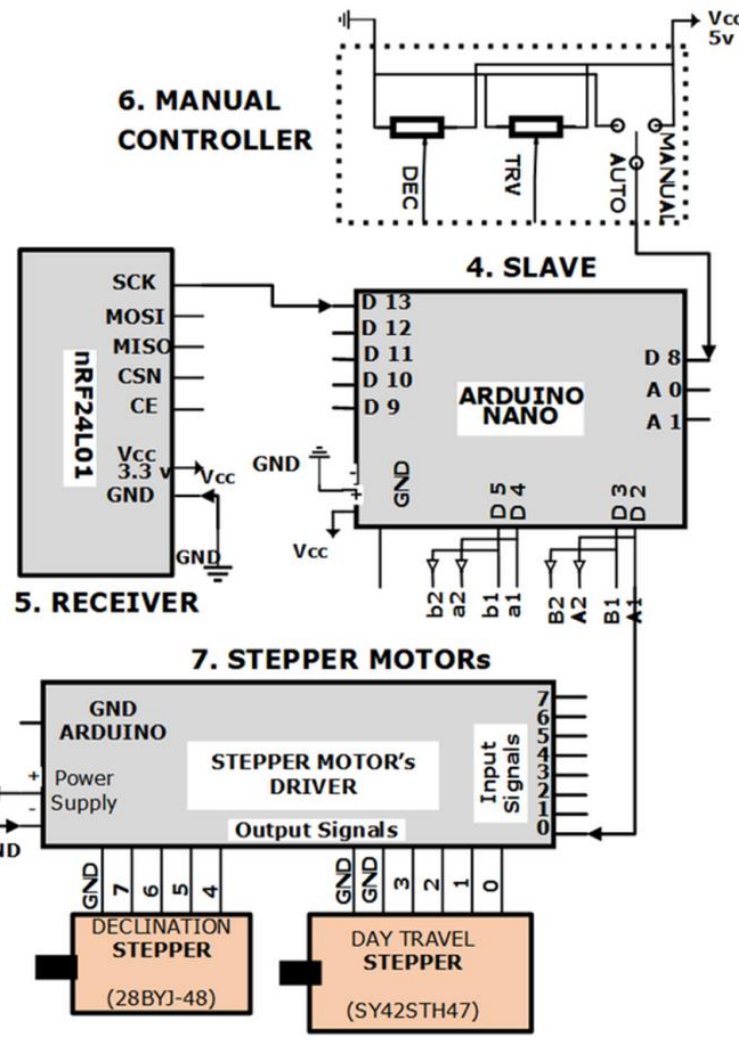

Fig.5 Solar tracking machine control unit

Here, the MCC sends signals (communicates) wirelessly to the three Receiving Centers located at each of the three Tracking Machines as shown in Fig. 2A whereas wireless communication also exists between Fault Detection Stations located with each of the machines and MFDC.

There are two motors per tracking machine driven by their respective drivers. One motor M1 is used for the tracking motion and the other one, M2 is used for the change in declination where the adjustment in the declination starts at mid-night.

The solar panel mounted on the tracking frame is shown in Fig. 2A. The tracking motion starts at 6 in the morning to 6 in the evening at the rate equal to the spin rate of the earth but in opposite direction to that of the earth. Further to this, the motor M1, a stepper motor, had rotation rate of 1.8 degrees (one full step) in 3.231 seconds. With the gear reduction, the angle through which the solar panel turns per step was equal to 0.0135 degrees. For 180 degrees rotation of the panel, it needed a total number of 13333 steps. The declination stepper motor, M2, turns 5.625 degrees per step. With the gear reduction, the panel turns $4.395 \mathrm{x}$ $10^{(-3)}$ degrees per step.

The declination values were calculated using a formula given in (Sharan A. M., 2011) and the calculated angles for days of a year are shown in Fig. 2D.
The circuit diagrams for communication between MCU and the Receiving Station of the Machine 1 (left most) are shown in Figs 4 and 5. Fig. 5 shows the circuit diagram between the parts of the Machine 1. In Fig. 4, the signal from MCU is received by the receiver of the Machine 1 which is processed by the Arduino Nano and the sequences of the pulses are sent to the stepper motors' driver.

The Motor M1 is operated in three modes - (a) forward at the earth's spin rate but in opposite direction from 6 A.M. to 6 P.M. Here, the number of steps given are stored in a variable called 'angle'. When the value of 'angle' reaches the total number of steps $(13,333)$ in the forward direction then the forward motion stops.

In the reverse direction from 6 P.M. to 9 P.M., the steps are given at the 4 times the spin rate of the earth to make the reverse period one fourth of the forward period. During the reverse period, the pulses' numbers are subtracted from

There is an added condition in the program for the forward to stop the motion when the clock, shown in Fig. 4, reads 6 P.M. In other words, the forward motion stops when either 'angle' variable takes the value of the maximum specified or the clock specifies 6 P.M. whichever happens first.

The change of the declination angle process starts at midnight. In Fig. 3, the declination motor is represented by $\mathrm{M} 2$. The details of the circuit diagram are shown in Fig. 5. The connections are made as per Table 2. In Fig. 2D, the reference or the zero value corresponds to March 21 declination value. If we refer to Fig. 2A, on this day, both inner and outer frames are coincident in the side view. When the declination values are negative, then the north part of the inner frame will be above the outer frame and vice versa. Fig. 5 also shows a Manual Control.

This is used when the machine unit sends a fault signal to the MFDC. This signal is sent when the motor stops operating after a power failure which can happen during the motion in the forward or reverse direction. In the manual operation, motion is given using a potentiometer (voltage divider) to the Arduino Nano, which converts this into digital signal for the forward or reverse direction. The motor speed is dependent upon the magnitude of the analog potential value. When the potentiometer is turned clockwise from the middle, 2.5 Volts, it will turn the stepper motor in the forward direction and vice versa.

\subsection{Signalling for Fault Detection}

If we see Fig. 6, the stepper motors' driver is shown on the top. 


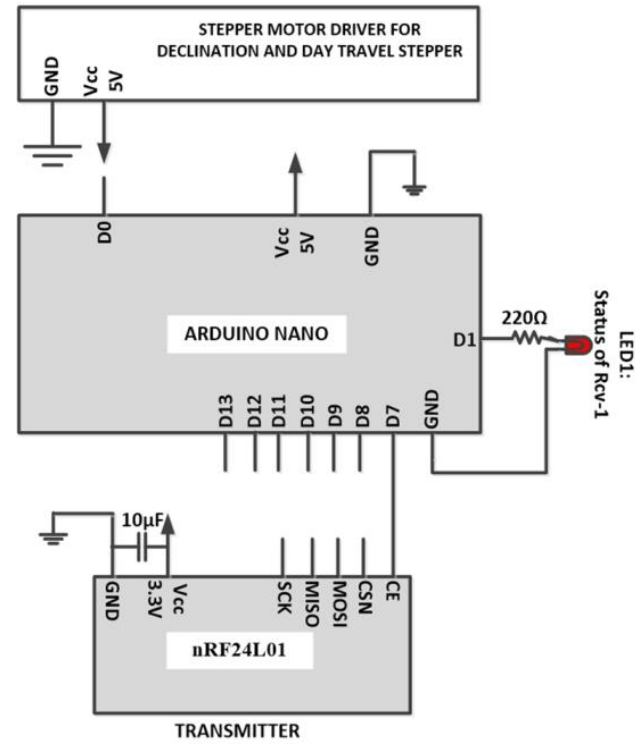

Fig.6 Fault detection and transmitting unit-1

In case of fault when the stepper motors stop, the voltage at the common collector (Vcc) pin of the driver goes to zero instead of 5 Volts that is shown in the figure. The Arduino turns the light emitting diode (LED) shown on the right side connected to D1 where $\mathrm{D}$ refers to digital pin of the Arduino. At the same time, the Arduino sends the fault signal to MFDC (refer to Fig. 3) via RF module shown at the bottom of the Fig. 6. It should be noted that in Fig. 6, all the connections are given in the Table 3. Fig. 7 shows the arrangement at the MFDC which is shown in Fig. 3.

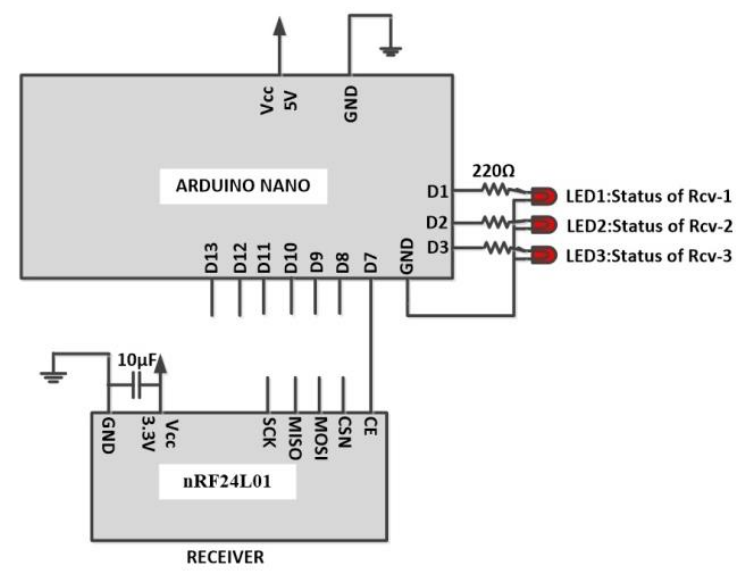

Fig.7 Control room fault monitoring (Receiving) Unit

The Arduino in Fig. 7 receives the fault signals via RF receiver shown at the bottom of the figure. The fault signals that this RF receives are sent from all of the machines separately. The Arduino can distinguish these separate signals from the machines and can turn the corresponding LED on which are shown on the right side. The three LEDs shown on the right correspond to the three sets of the machines used in the experiments. Fig 8 shows other experimental details.

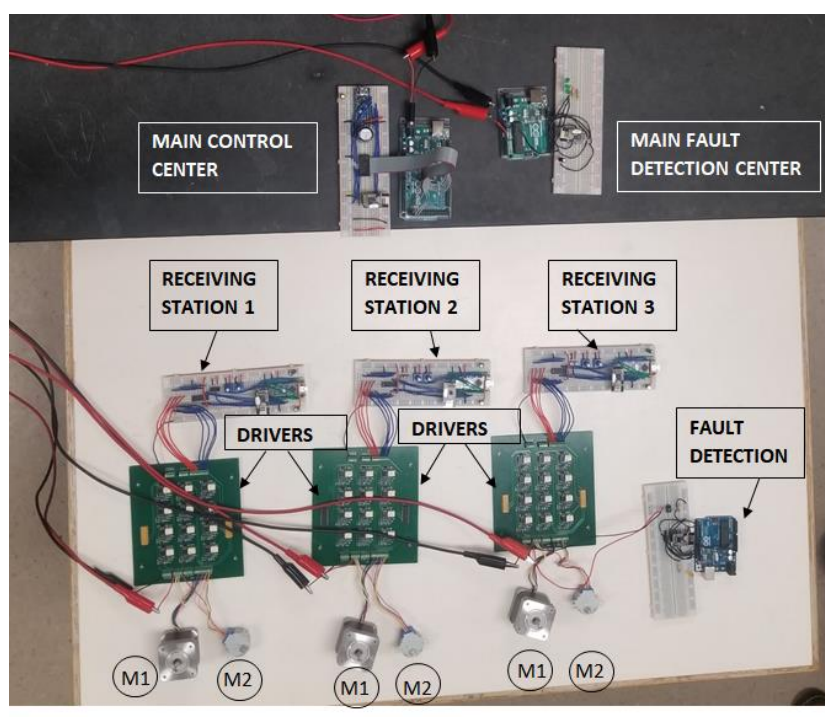

Fig.8 A photograph of the experimental setup

Tables 1 to 4 show various connections. For circuit details and programming, one can refer to (Language Reference, 2019, https://www.arduino.cc/reference /en/), (Time library for Arduino, 2019, https://github.com/ Paul Stoffregen/ Time), (Arduino Wireless Communications - NRF24L01 Tutorial, 2019, https:// howtomechatronics.com/ tutorials/arduino/ arduino-wireless-communication-nrf24101-tutorial/)

Table 1 Wire Connections in fig. 4

\begin{tabular}{|c|c|c|}
\hline $\begin{array}{c}\text { ARDIO MEGA } \\
\text { pins }\end{array}$ & $\begin{array}{c}\text { ARDUINO NANO } \\
\text { pins }\end{array}$ & Nrf24101 pins \\
\hline (1.Master) & (2.Time) & (3.Transmitter) \\
\hline D10 & D10 & \\
\hline D 9 & D9 & \\
\hline D 8 & D 8 & \\
\hline D 7 & D 7 & \\
\hline D 6 & D 6 & CE \\
\hline D 5 & D 5 & CSN \\
\hline D 4 & D 4 & MISO \\
\hline Analog 3 & PWM 3 & MOSI \\
\hline D 48 & & SCK \\
\hline D 49 & & Vcc (3.3 v) \\
\hline D 50 & & GND \\
\hline D 51 & & \\
\hline D 52 & Vcc (5 v) & \\
\hline Vcc (5 v) & GND & \\
\hline GND & & \\
\hline
\end{tabular}

Table 2 Wire Connections in fig. 5

\begin{tabular}{|c|c|c|c|}
\hline $\begin{array}{c}\text { ARDIO NANO } \\
\text { pins }\end{array}$ & Nrf24101 pins & $\begin{array}{c}\text { (3.MANUAL } \\
\text { CONTROLLER) }\end{array}$ & $\begin{array}{c}\text { (4. STEPPER } \\
\text { MOTORs) }\end{array}$ \\
\hline (1. SLAVE) & (2. RECEIVER) & & \\
\hline D 9 & CE & & \\
\hline D 10 & CSN & & \\
\hline D 11 & MOSI & & \\
\hline D 12 & MISO & & \\
\hline D 13 & SCK & & \\
\hline D 8 & & Switch & \\
\hline Analog 0 & & $\begin{array}{c}\text { Potentiometer- } \\
\text { TRV }\end{array}$ & \\
\hline Analog 1 & & $\begin{array}{c}\text { Potentiometer- } \\
\text { DEC }\end{array}$ & In 0 \\
\hline A1 & & & \\
\hline
\end{tabular}




\begin{tabular}{|c|c|c|c|}
\hline B1 & & & In 1 \\
\hline A2 & & & In 2 \\
\hline B2 & & & In 3 \\
\hline a1 & & & In 4 \\
\hline b1 & & & In 5 \\
\hline a2 & & & In 6 \\
\hline b2 & & Vcc $(5 \mathrm{v})$ & In 7 \\
\hline Vcc $(5 \mathrm{v})$ & Vcc $(3.3 \mathrm{v})$ & & Vcc $5 \mathrm{v}$ \\
\hline
\end{tabular}

Table 3 Wire Connections in fig.6

\begin{tabular}{|c|c|c|c|c|}
\hline 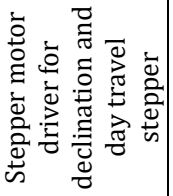 & 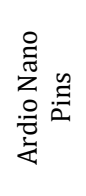 & 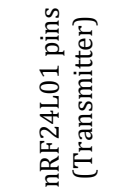 & త్త & 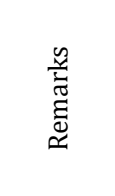 \\
\hline \multirow[t]{9}{*}{$\operatorname{Vcc}(5 \mathrm{v})$} & D0 & & & \\
\hline & D 1 & & $\begin{array}{l}\text { LED Anode } \\
\text { leg is } \\
\text { connected } \\
\text { with } 220 \\
\text { Ohm } \\
\text { Resistor }\end{array}$ & $\begin{array}{l}\text { Status of } \\
\text { Rcv-1 (if } \\
\text { fault, } \\
\text { flashing) }\end{array}$ \\
\hline & D 7 & $\mathrm{CE}$ & & \\
\hline & D 8 & CSN & & \\
\hline & D 11 & MOSI & & \\
\hline & D 12 & MISO & & \\
\hline & D 13 & SCK & & \\
\hline & $\begin{array}{c}\text { Vcc (5 } \\
\text { v) }\end{array}$ & $\operatorname{Vcc}(3.3 \mathrm{v})$ & & \\
\hline & GND & & $\begin{array}{c}\text { LED } \\
\text { Cathode leg } \\
\text { is } \\
\text { terminated }\end{array}$ & $\begin{array}{l}\text { Status of } \\
\text { Rcv-1 (if } \\
\text { fault, } \\
\text { flashing) }\end{array}$ \\
\hline
\end{tabular}

Table 4 Wire Connections in fig. 7

\begin{tabular}{|c|c|c|c|}
\hline $\begin{array}{l}\text { Arduino } \\
\text { nano pins }\end{array}$ & $\begin{array}{l}\text { Nrf24l01 } \\
\text { pins } \\
\text { (receiver) }\end{array}$ & Led & Remarks \\
\hline \multirow[t]{2}{*}{ D1 } & & $\begin{array}{l}\text { LED1 Anode leg } \\
\text { is connected } \\
\text { with } 220 \mathrm{Ohm} \\
\text { Resistor }\end{array}$ & Status of Rcv-1 \\
\hline & & & $\begin{array}{l}\text { (if fault, } \\
\text { flashing) }\end{array}$ \\
\hline \multirow[t]{2}{*}{ D2 } & & $\begin{array}{l}\text { LED2 Anode leg } \\
\text { is connected } \\
\text { with } 220 \mathrm{Ohm} \\
\text { Resistor }\end{array}$ & Status of Rcv-2 \\
\hline & & & $\begin{array}{l}\text { (if fault, } \\
\text { flashing) }\end{array}$ \\
\hline D3 & & $\begin{array}{l}\text { LED3 Anode leg } \\
\text { is connected } \\
\text { with } 220 \text { Ohm } \\
\text { Resistor }\end{array}$ & $\begin{array}{l}\text { Status of Rcv-3 } \\
\text { (if fault, } \\
\text { flashing) }\end{array}$ \\
\hline D7 & $\mathrm{CE}$ & & \\
\hline D8 & CSN & & \\
\hline D11 & MOSI & & \\
\hline D12 & MISO & & \\
\hline D13 & SCK & & \\
\hline $\operatorname{Vcc}(5 \mathrm{v})$ & $\operatorname{Vcc}(3.3 v)$ & & \\
\hline GND & & $\begin{array}{l}\text { LED1, } 2 \text { \& } 3 \\
\text { Cathode leg is } \\
\text { terminated }\end{array}$ & $\begin{array}{c}\text { Status of Rcv-1, } \\
2 \text { \& } 3 \text { (if fault, } \\
\text { flashing) }\end{array}$ \\
\hline
\end{tabular}

\section{Conclusion}

In this work, the analysis was done for single axis and dual axis tracking processes that require use of photosensors for position control. In these methods, if there are several machines, then each of the machines operate independent of the others as the atmospheric conditions can defer from machine to machine. Therefore, management of such collection of such machines for power generation becomes tedious and complex.

However, if one uses machines such as shown in Fig. 2A, then the tracking depends upon the position of the earth with respect to the Sun. In this case, the Sun's rays are incident on all machines at a particular angular orientation. In other words, the condition is global rather than being local. In such cases, one can control the entire collection from a single location which in our case is called MCC.

In addition, in this work, the wireless technology is used for sending the signals from MCC to individual machines and detecting the faults at the machine level. The advantage of wireless technology is that one does not have to lay cables connecting the MCC to individual machine and vice versa.

\section{References}

Statistics Key World Energy Trends Excerpt from: World Energy Balances, 2016, https://www.iea.org/ publications/freepublications/publication/KeyWorld2017 .pdf

M. Şenol, S. Abbasoğlu, O. Kükrer, A.A. Babatunde, 2016, A guide in installing large-scale PV power plant for self consumption mechanism, Sol. Energy. 132 - 518-537.

Global status report,2017. http://www.ren21. net/gsr_2017_full_report_en.

Department of Energy- Global Energy Storage Database, 2016 , www.energystorageexchange.org

K. Zhang, K.J. Shen, J. Zhang, and H. Han, 2019, Recent Advances on Renewable Energies and Carbon Capture . Polish Journal of Environmental Studies. doi:10.15244/pjoes/93711.

J.C.Hou, , M.C. CAO,and P.K. Liu, 2018, Development and Utilization of Geothermal Energy in China: Current Practices and Future Strategies, Renewable Energy, 125, 401.

A.M. Sharan ,2008, Variation of Energy Conversion Efficiencies of Stationary Photovoltaic Systems with Latitudes, Energy and Environment, Vol 19, No 5, pp 679689.

S. Aziz ,and M. Hassan , 2019, Dual Axis Solar Tracker for Solar Panel with Wireless Switching . In: Nath V., Mandal J. (eds) Proceeding of the Second International Conference on Microelectronics, Computing \& Communication Systems (MCCS 2017). Lecture Notes in Electrical Engineering, vol 476. Springer, Singapore.

T.S. Zhan, W.Lin,M. Tsai.,and G. Wang, 2013, Design and Implementation of the Dual-Axis Solar Tracking System, in Computer Software and Applications Conference (COMPSAC), IEEE 37th Annual. 
S., Chakrabory, N.Mukherjee, R. Biswas, T.Saha, A. Mohinta, N.K. Modi, and D.P., Samajdar, 2015, Microcontroller based Solar Tracker system using LDRs and Stepper Motor, in International Conference on Microelectronic Circuit and System (Micro-2015).

D. Cooke, 2011, Single vs Dual Axis Solar Tracking, Alternate Energy eMagazine, April 2011

A.M. Sharan, and M. Prateek, 2006, Automation of Minimum Torque Based Accurate Solar Tracking Systems Using Microprocessors , Journal of Indian Institute of Science, Sept - Oct. , pp . 415 - 437.
A.M. Sharan A. M., 2011, Optimal Conversion of Solar Energy of Statically Mounted Systems in India, Asian Journal of Water, Environment and Pollution, Vol 8,No 2, pp 17-23.

Language Reference, 2019, https://www.arduino.cc/ reference/en/

Time library for Arduino, 2019, https://github.com/ PaulStoffregen/Time

Arduino Wireless Communications - NRF24L01 Tutorial, 2019, https://howtomechatronics.com/ tutorials/arduino /arduino-wireless-communication-nrf24l01-tutorial/ 